\title{
Knowledge, Attitude and Health Belief (KAHB) on Cancer and Its Treatment: Qualitative exploration of cancer patients in Penang, Malaysia
}

\author{
Che Noriah Othman ${ }^{1}$, Syed Azhar Syed Sulaiman², Maryam Farooqui ${ }^{3}$, Wan Ismahaniza Ismail ${ }^{4}$ \\ 1 Faculty of Pharmacy, Universiti Teknologi MARA, Cawangan Pulau Pinang, Kampus Bertam, 13200, Pulau Pinang, Malaysia, \\ ${ }^{2}$ School of Pharmaceutical Sciences, Universiti Sains Malaysia, 11800, Pulau Pinang, Malaysia \\ 3 Unaizah College of Pharmacy, Qassim University, Saudi Arabia. Saudi Arabia, PO BOX 5888 Unaizah 51911, Qassim, Saudi Arabia. \\ ${ }^{4}$ Faculty of Allied Health Sciences, Universiti Teknologi MARA, Cawangan Pulau Pinang, , 13200, Pulau Pinang, Malaysia,
}

chenoriah.othman@uitm.edu.my, sazhar@usm.my, maryamfarooqui.uitm@gmail.com, ismahanisa@uitm.edu.my

Tel: 60134885485

\begin{abstract}
KAHB toward cancer and its treatment determines the patients' clinical outcome. This study explored KAHB among cancer patients in Penang, Malaysia. Sixteen cancer patients were interviewed upon saturation. This study recorded the information, transcribed, translated and validated before coded and categorized into themes. The study showed that perceived knowledge of cancer and its treatment was moderate. Their attitude toward cancer and its treatment was positive; however, revealed various health belief which influences their cues to action. Most patients seek traditional treatment besides modern medicine as they felt better. This information can support health caregivers for better patient's management.
\end{abstract}

eISSN: 2398-42870 2021. The Authors. Published for AMER ABRA cE-Bs by e-International Publishing House, Ltd., UK. This is an open access article under the CC BYNC-ND license (http://creativecommons.org/licenses/by-nc-nd/4.0). Peer-review under responsibility of AMER (Association of Malaysian Environment-Behaviour Researchers), ABRA (Association of Behavioural Researchers on Asians/Africans/Arabians) and CE-Bs (Centre for Environment-Behaviour Studies), Faculty of Architecture, Planning \& Surveying, Universiti Teknologi MARA, Malaysia.

DOI: https://doi.org/10.21834/ebpj.v6i16.269

\subsection{Introduction}

Knowledge, attitude and health belief (KAHB) are very important aspect of the study (Nikbakhsh et al., 2014). These three components are closely related and intertwined with each other. The parameters are also influenced by socio-cultural, economic, educational, and religious beliefs (Farooqui et al., 2011), which determine the direction of patient care as illustrated in the Health Belief Model (HBM) (Conner \& Norman, 2005).

Knowledge, attitude, and health belief (KAHB) determine patients' attitude toward treatment compliance, thus better clinical outcome that might change their health related quality of life. KAHB is various among sociodemographic and economic of the patients (Nikbakhsh et al., 2014). In Malaysia however, the KAHB about cancer and its treatment effectiveness were not yet explored. Since socioeconomic status, culture, religion and gender were identified to be among the factors that influence knowledge attitude and health belief, it is eminent to explore the issue in depth to understand the issue better to help policy maker to design a proper awareness campaign or education to catch up with the current type of patients. Qualitative exploration help this study to explore the issue in depth. The knowledge and adherent to knowledge change over time and technologies available influence patients' attitudes. The socioeconomic and cultural background may change along with the shift in the standard of living.

eISSN: 2398-4287C 2021. The Authors. Published for AMER ABRA cE-Bs by e-International Publishing House, Ltd., UK. This is an open access article under the CC BYNC-ND license (http://creativecommons.org/licenses/by-nc-nd/4.0/). Peer-review under responsibility of AMER (Association of Malaysian Environment-Behaviour Researchers), ABRA (Association of Behavioural Researchers on Asians/Africans/Arabians) and cE-Bs (Centre for Environment-Behaviour Studies), Faculty of Architecture, Planning \& Surveying, Universiti Teknologi MARA, Malaysia.

DOI: https://doi.org/10.21834/ebpj.v6i16.269 
Moreover, the growth in Traditional and Complementary Medicine in the market drives people toward a new option of thinking (Che Noriah and Farooqui 2018). This study was conducted to explore cancer patients' knowledge, attitude and health belief among cancer patients in Penang Malaysia.

\subsection{Objective of the study:}

The objective of the study were:

-to explore cancer patients' knowledge on cancer and its treatment approach.

-to explore cancer patients' attitude toward cancer and its treatment approach.

-to explore cancer patients health belief on cancer and its treatment approach.

\subsection{Literature review}

Knowledge, attitude, and health belief on cancer are eminent for exploration because they reported the increasing incidence of late presentation of cancer stage among the Malaysian population (Norsa'adah et al.,2011). Lack of knowledge on healthy lifestyle and poor attitude on cancer were among the reasons (Maryam et al., 2011). Social and cultural perception and strong beliefs in alternative therapies are other reasons for advanced-stage presentation (Khan, Leong \& Ming, 2015). Due to most patients reported at a late stage of cancer, The National Cancer Control Program is working hard to reduce the cancer incidence and the mortality rate and improve the patients' quality of life. The only approach that seems useful is through awareness campaign and education to change people's mindset toward cancer and the treatment offered. More patients will come forward when they detect some abnormality in their bodies. Information on KAHB among cancer patients is crucial to help the government achieve its goal (Lim 2002).

Attitude towards the causes of cancer and its treatment effectiveness is highly dependent on peoples' social and cultural backgrounds. The health belief model explains how people believe about their health problems, perceived benefits, and attitude toward their belief (Marmara et al., 2017). Despite the campaign initiated worldwide, people only turned to the hospital when the cancer was already at the incurable stage (Maryam et al., 2011). We conducted this study using a qualitative method to explore the issue in depth. Qualitative exploration helped us to know in detail the cancer patients' knowledge, attitude, and health belief toward cancer and its treatment and how they perceived the effectiveness of conventional cancer treatment for their disease healing. This information is essential for health caregivers to design a suitable awareness program to complement patients' knowledge gap. Sufficient knowledge, correct attitude, and health belief on cancer and its treatment effectiveness are essential to help patients' decision making.

Due to lack of knowledge and poor attitude, and negative health belief, most patients came to the doctor at a late stage of the disease. The National Cancer Control Program aims to reduce cancer incidence and mortality and improve cancer patients' quality of life. Policies encompass prevention, early diagnosis, treatment, palliative care, and rehabilitation through the education program.

Since the last comprehensive review in 1974, the Health Belief Model (HBM) has continued to focus on considerable theoretical and research attention (Janz \& Becker, 1984). Many studies are indicating the role of knowledge and health belief on patients' performance cancer screening (Dine et al., 2017), mammography practice (Aflakseir \& Abbasi, 2012) and treatment decision making (Herrmann, Hall, \& Proietto, 2018). A low level of knowledge suggested the negative attitude (Ramathuba et al., 2015: Gebresillassie et al., 2018) even with a less perceived barrier (Aldohaian et al., 2019).

As far as Malaysian cancer patients are concerned, a study conducted on the different ethnic groups of cancer patients reported that most respondents never heard of cancer screening before diagnosis. Some of them have listened to mammograms and Pap smear tests but never go for screening due to a lack of personal susceptibility. Some of the barriers reported were lack of knowledge and money constraint. This study suggested disseminating more campaign toward cancer screening with a better prevention method than cure (Maryam et al., 2013). It is important to explore cancer patients' knowledge about cancer because it relates to the patients' adherent to medication. Social and cultural backgrounds play a vital role in determining one's attitude (Lim et al., 2009). The meanings of cancer may be different ethnic groups. Some indigenous groups cannot well-define the word cancer in their native language (Dein, 2004), (Baisch, Vang, \& Peterman, 2008). In some, cancer is considered an incurable disease related to magic, bad luck, or God's punishment. More or less, the same scenario is observed in developing countries (Sheikh \& Ogden, 1998). Some came with the advanced stage presentation due to the strong belief in alternative therapy and negative social and cultural perception (Sheikh \& Ogden, 1998) : (AshingGiwa et al., 2004) : (Maryam et al 2013). One published data in Malaysia reported that breast cancer patients seek treatment after 2 to 36 months of diagnosis. Some $(60 \%)$ of them go for alternative therapy despite numerous efforts by the government to improve cancer awareness (Abdullah and Cheng 2004). Early detection, seeking proven treatment at curable stages and patients' adherence to the cancer treatments are some of the important steps in prolonging the length and quality of life of cancer patients as well as reducing the cancer burden on the health care system.

Malaysia is a country of multi-ethnic populations with different cultural and educational backgrounds; thus, the evaluation of knowledge and perceptions of cancer and its treatment will be both fascinating and time-consuming but necessary for a greater understanding of the late causes presentations (Maryam et al., 2013). The patients' health belief is based on the components in the Health Belief Model (HBM) shown in figure 1.1. 


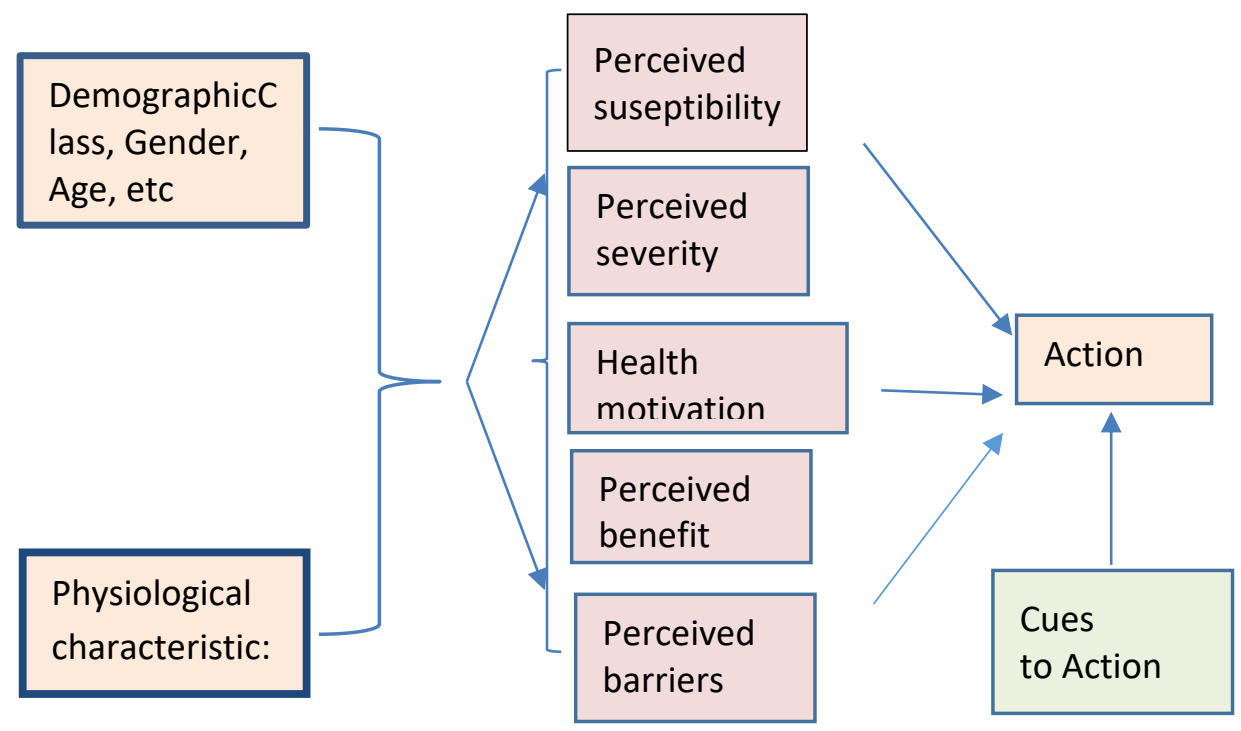

Figure 1.1: The components of behaviours in Health Belief ModelT (HBM) (Conner \& Norman, 2005)

\subsection{Methodology.}

This study was conducted on a group of cancer patients attending MAKNA (Majlis Kanser Negara) monthly activities in Penang from January to April 2019. All cancer patients age 18 years old and above were consented to participate in this study. Face-to-face interviews were conducted using a semi-structured interview guide developed from an intensive literature search. The semi-structured interview guide was based on 1. Perceived Knowledge of cancer and conventional treatment received.2. Attitude toward cancer, the treatment received. 3.1 Perceived effectiveness of traditional therapy for cancer healing 3.2 Barriers to modern treatment of cancer seeking. Perceived efficacy and barriers for conventional cancer treatment are under the sub-theme of Health Belief. 4. Cue to action.

Treatment Field notes were applied when necessary to ensure no information missed. Specific probes and field notes were used during the pilot interviews to make sure no information cut. The subsequent discussion modified with the new question added. Patients coding were based on P1 until P21.

P5, P6 and P7 were excluded from the study because the data was not complete. The interviews were repeatedly conducted one after another until we reached saturation, i.e., no further information detected in the three subsequent interviews. The data were then analyzed according to the standard content analysis framework using the N-Vivo program.

After the transcribing process, the validation made by sending to the informants for clarification. The validated data were translated and categorized before forming suitable themes. The result was presented in table and narrative form.

The flow chart of the qualitative analysis is illustrated in figure 1.2

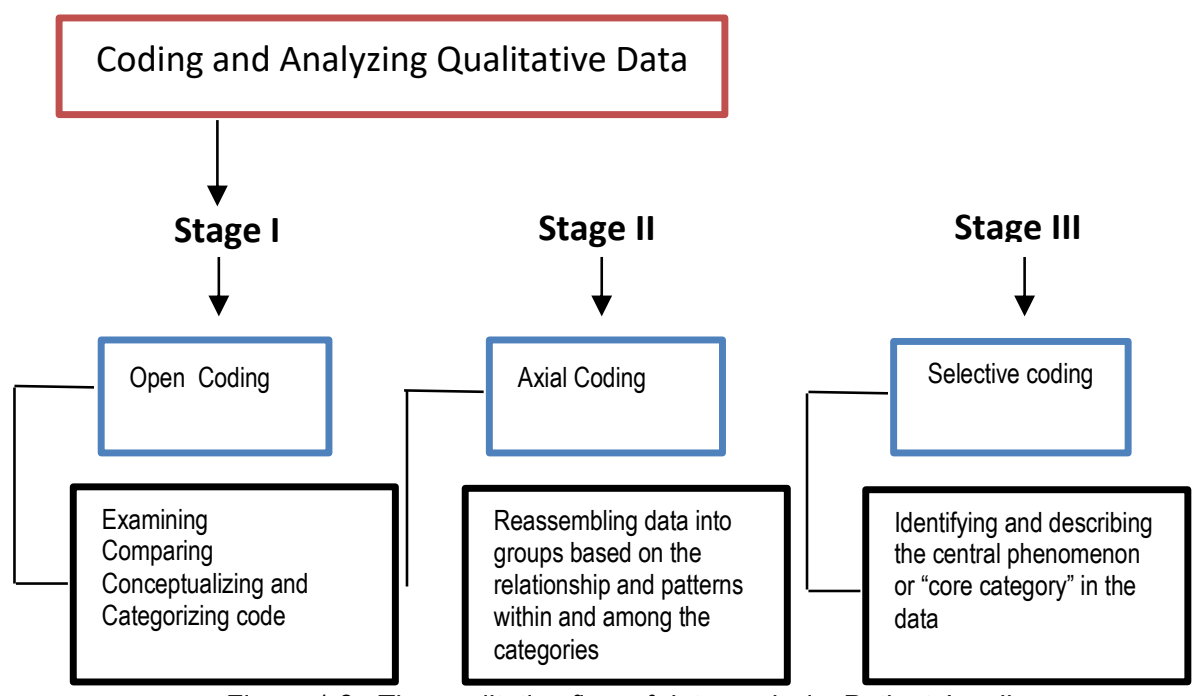

Figure 1.2 : The qualitative flow of data analysis. Patients' coding: 


\begin{tabular}{|l|l|l|l|l|l|}
\hline $\begin{array}{l}\text { Coding } \\
\text { Number }\end{array}$ & $\begin{array}{l}\text { Patients' } \\
\text { age }\end{array}$ & & & Cancer Type & Stage \\
\hline P1 & 33 & Female & Malay & Breast & 4 \\
\hline P2 & 60 & Male & Chinese & Colon & 2 \\
\hline P3 & 40 & Male & Malay & Colon & 2 \\
\hline P4 & 35 & Female & Malay & Nasopharnygeal & 2 \\
\hline P5 & X & X & X & X & X \\
\hline P6 & X & X & X & X & X \\
\hline P7 & X & X & X & X & X \\
\hline P8 & 25 & Female & Malay & Breast & 4 \\
\hline P9 & 62 & Female & Malay & Breast & 4 \\
\hline P10 & 40 & Female & Chinese & Liver & 4 \\
\hline P11 & 59 & Female & Malay & Breast & 2 \\
\hline P12 & 52 & Female & Indian & Breast & 2 \\
\hline P13 & 57 & Female & Malay & Breast & 2 \\
\hline P14 & 50 & Female & Malay & Breast & 2 \\
\hline P15 & 52 & Female & Malay & Colon & 3 \\
\hline P16 & 55 & Female & Malay & Bresat & 4 \\
\hline P17 & 60 & Female & Malay & Cervical & 1 \\
\hline P18 & 60 & Female & Malay & Brain & 4 \\
\hline P19 & 35 & Female & Malay & Cervical & 2 \\
\hline P20 & 38 & Female & Malay & Breast & 2 \\
\hline P21 & 65 & Female & Indian & Breast & 2 \\
\hline
\end{tabular}

\section{Ethical Approval}

This study obtained ethical approval from the School of Pharmaceutical Sciences, USM and Lam Wah Ee Hospital on Clinical Studies in Malaysia (Reference: (USM-HLWE/IEC/2018 (0002)).

After the transcribing process, the validation made by sending to the informants for clarification. The validated data were translated and categorized before forming suitable themes. The result was presented in table and narrative form.

\section{Results}

\subsection{Demographic data.}

Eighteen cancer patients ( $P 1$ to $P 4$ and P8 to P21) aged between 25 to 72 years old (Mean age=49.4 SD+/-13.1). (P5, P6, P7) were excluded from the study due to incomplete information. The highest percentage was contributed by the group age of $51-60$ years old $(38.9 \%)$, Malay $(n=14,77.8 \%)$ and from the middle to low-income income group $(n=17,88.8 .5 \%)$. Most of them were from secondary education ( $n=8,44.4 \%)$ presented with various cancer stages. However, $55.6 \%$ of them were at late stages (3 and 4). Breast cancer patients dominated the percentage $(61.1 \%, n=11)$. Table 1 shows the detail demographic, socioeconomic and disease characteristics of the informants.

\subsubsection{The demographic, socioeconomic and disease characteristic of respondents}

Table 1: The demographic characteristic of the respondents.

\begin{tabular}{|l|l|l|}
\hline Characteristic & N=18 & $\%$ \\
\hline Age (Mean=49.4 SD +/-13.1 Years old) & & 11.1 \\
\hline $18-30$ & 2 & 27.8 \\
\hline $31-40$ & 5 & 5.6 \\
\hline $\mathbf{4 1 - 5 0}$ & 1 & 38.9 \\
\hline $\mathbf{5 1 - 6 0}$ & 7 & 11.1 \\
\hline $\mathbf{6 1 - 7 0}$ & 2 & 5.6 \\
\hline $\mathbf{7 0}$ & 1 & \\
\hline Gender & & 11.1 \\
\hline Male & 2 & 88.9 \\
\hline Female & 16 & \\
\hline Race & & 77.8 \\
\hline Malay & 14 & 11.1 \\
\hline Chinese & 2 & 11.1 \\
\hline Indian/Sikh & 2 & \\
\hline Religion & & \\
\hline Islam & 14 & 77.8 \\
\hline Buddist & 2 & 11.1 \\
\hline Hindu/Sikhism & 2 & 11.1 \\
\hline
\end{tabular}


Table 2 :The Education level of respondents.

\begin{tabular}{|l|l|l|}
\hline Characteristic & N=18 & $\%$ \\
\hline Educational status & & \\
\hline Primary & 2 & 16.7 \\
\hline Secondary & 9 & 50.0 \\
\hline Diploma/Matriculation/Degree/Master/PhD & 6 & 33.3 \\
\hline
\end{tabular}

Table 3: The Socioeconomic status of respondents.

\begin{tabular}{|l|l|l|}
\hline Socioeconomic status & 6 & 33.3 \\
\hline Low (Less RM 1500/month) & 10 & 55.5 \\
\hline Middle (1500-3500/month) & 2 & 11.1 \\
\hline High (>3500/month) & 2 & \\
\hline
\end{tabular}

Table 4: The Disease characteristic of respondents.

\begin{tabular}{|l|l|l|}
\hline Cancer site & 3 & 16.7 \\
\hline Colorectal & 11 & 61.1 \\
\hline Breast & 2 & 11.1 \\
\hline Cervix & 1 & 5.6 \\
\hline Nasopharangeal & 1 & 5.6 \\
\hline Others & & \\
\hline Cancer stage & 7 & 38.9 \\
\hline Very advanced (Stage 4 Metastasis) & 3 \\
\hline Slightly advanced (Stage 3 No metastasis) & 16.7 \\
\hline Not advanced at all.(Stage 1 and 2) & 8 & 44.4 \\
\hline
\end{tabular}

\subsection{Patients' knowledge, attitude and health belief on cancer and its treatment approaches.}

After the analysis, this study identified four themes. i) Knowledge on Cancer, and treatment received ii) Attitude toward Cancer and treatment received (iii) Perceived effectiveness on treatment acquired.

\subsubsection{Perceived Knowledge on cancer and conventional treatment received.}

Most of the patients understand their disease in general but limited knowledge of how cancer happens and what kind of medicine they were receiving. However, in term of procedures, they understood it very much.

"I know everything about cancer. I know everything about my cancer the diagnosis and the people who can get them and what is my risk of getting cancer because I am in a medical doctor. It was stage 3b. But recently after my PET Scan, it was considered at stage 4 because they found one small stripe at my acetabulum, which is very rare for breast cancer". (P1)

"My cancer could be due to stress". (P3)

"I know cancer is is a growth and is a hereditary". (P1 and P5, hereditary (P7).

However, some patients said it is due to bacteria.

"Cancer is a disease. It has bacteria. I understand bacteria only, and I don't know how it happens". (P3).

Worst still, some patients don't know what cancer is.

"I don't know what cancer is, but I know it can cause death". (P4, P7)

"I only know a little bit about cancer" (P6, P9).

Most patients understand the type of treatment offered to them.

"The biopsy was taken..it was confirmed cancer stage 2" (P3)

"My cancer has gone to the bone and the ribs bones". (P8)

"I know I have breast cancer and is stage 4".(P9).

My cancer could not be operated because it was already staged 4, the doctor said the chance of survival was $50 \%$ and would only stand for 6 to 7 months. (P18).

I have Cervical Cancer, stage 2. (P19)

First time it was four years ago. This cancer is a second breast. The doctor said it is suspected on staged 2. (P21). 
Chemo has finished for six times. The remaining treatment is seven cycles for the still-active cancer that have gone to the bone. We don't have chemotherapy for bone (P8).

4.2.2 Attitude toward cancer, the treatment received.

Patients showed a positive attitude toward cancer treatment by the action taken by them.

"I went to do the scope at private hospital." (P2).

"I Know that if taken out early can save live".(P7)

"I never suspect anything this bad...no symptom...only fever and diarrhea once in a while. Only thing is 3 to 4 months before the operation the bleeding was quiet bad" $P 3$.

"I am very confident about the treatment I receive (P2, P3, P5, P6, P7).

"First, I felt the pain on my stomach area. I went to see a doctor it was in 2018. Then started chemotherapy. I had a second operation on Feb 2019 after that I undergo chemotherapy and now is my third time." (P10).

"I know about my cancer when it was at the size of a matches head". (P13).

"I came to know about my cancer when I felt something hard on my breast". (P14)

"I had cancer in 2014 when my I did not have my period for almost 1 year". (P17).

"I always have pain on my arm, but friends said that was common. I felt the lump under my arm, numbness on hands and legs". (P18).

"I just went for general checking. Doctor suspected something and send me for scanning. And it confirmed that I had endometriosis". (P19)

"I did not feel anything at first, feel like doing the test to check whether my body was ok or not. The whole family went for the test, they did not get it, so I too went, .and I got it. (P2)

However, there was a case where the doctor failed to detect the cancer on regular follow up.

"I always went for normal check-up. But the cancer was not diagnosed. I myself felt the lump, then went for check-up. But is was already big when the doctor found the cancer, Dr said it was stage 2". (P21).

4.2.3 Health belief on cancer, its treatment effectiveness for cancer healing.

Health belief on cancer was divided into three categories i) Perceived effectiveness on the conventional treatment received for cancer healing ii) Barriers for cancer treatment.

4.2.3.1 Perceived effectiveness on conventional treatment for cancer healing.

Most of them believe that modern treatment can cure their disease.

"I am very confident on the treatment I receive. I am confident that my cancer can heal with the current "(P2, P3, P4, P5, P7, P8).

However, one patient claimed that treatment is only our effort toward healing. The true healer is Allah SWT.

"It is only our effort toward healing the best. It is not us or the medicine that heel. If I belief that chemotherapy is the one that heel me is totally wrong. Allah is". (P1)

There were some patients reported to go for some spiritual healers and rukyah therapy.

"I went for traditional therapy but only for rukyah" (P4).

"I went to Perlis, he gave me bedak sejuk and air jampi" (P8).

\subsubsection{Barriers for conventional cancer treatment seeking}

Patients reported some barriers, such as:

"I cannot speak Malay". (P10)

"I am afraid that my cancer will spread. But whatever it is my mother is the priority".(P13) "I pity my children if I left for hospital treatment.". (P9)

"I cannot drive". (P13). 
"The side effects like giddiness, vomiting, it took two weeks to stabilize. Stress is high during chemo time. (P14).

"Money problem of course". (P8)

"I feel scared, to see the doctors, afraid of hospitals, and really afraid to stay in there".(P9)

\subsection{Discussion}

\subsubsection{Knowledge on cancer, conventional treatment received.}

Knowledge, attitude and health belief on cancer and its treatment are closely related to sociodemographic, socioeconomic and education. (Pasket et al., 2004). Sociodemographic, socioeconomic, and education affect cancer patients' belief and myths and affect their treatment decision making. (Kishore et al. 2008). However, this study showed that cancer knowledge is related to their education status rather than the cultural or religious background. Patients with a low level of education tend to understand cancer lightly and take them more easily compare to those with a higher level of education. This finding is in line with the study conducted by Chaka, et al., 2018, which revealed that patients with a higher education level have more knowledge about cancer. On the other hands, lower level of education causes the negative attitude among cancer patients on a study conducted among a group of cervical cancer patients in Zimbakwee (Tapera et al., 2019). Knowledge on cancer is important as early detection can safe life. (Laxmi \& Khan, 2013). However, this study found out that most of the patients came for an early diagnosis, revealing the attitude toward cancer is positive despite the poor knowledge. Therefore, it is important to regularly provide preventive cancer education at every group or education level, to increase community awareness about cancers. (Korkut, 2019).

They described in detail the procedures performed on them and what were the reason for the treatment. It shows that health care providers play a successful role in providing them with enough information. Relevant and understandable information is a prerequisite for patients to acquire enough knowledge to be actively involved in shared decision-making, comply with the treatment plan, be aware of potential side effects, and understand what to do if side-effects occur. As well-informed patients are more satisfied with the care, have a better sense of control over their entire situation and report better quality of life (Berger et al., 2018).

However, they were cases claimed by the patients that the cancer was not detected by the doctors even though they never miss the doctor's appointment for other diseases. Physicians can add to delays by failing to recognize signs and triage the right patients forward for further investigation. Education of both the patient and general physician is essential to move to an early diagnosis of Cancer WHO suggested that early detection of cancer only can be achieved through education to promote early diagnosis and screening. Misdiagnosed is one of the common reason for late detection worldwide. It was reported in 1 out of 10 patients ((Lancet 2010)).

\subsubsection{Attitude toward cancer, the treatment received.}

Most of the patients have a positive attitude toward the cancer they were suffering. They believed that cancer could be cured by the treatment they received. Patients followed the doctors' suggestion and followed the treatment schedule successfully. They were very committed to come for the treatment and believe that the disease was going to heal. Quality healthcare outcomes depend upon patients' adherence to recommended treatment regimens. Patients must be allowed to tell the story of their unique illness experiences. Knowing the patient as a person allows the health professional to understand crucial elements to the patient's adherence: beliefs, attitudes, subjective norms, cultural context, social supports, and emotional health challenges, particularly depression. Physician-patient partnerships are essential when choosing amongst various therapeutic options to maximize adherence. Mutual collaboration fosters greater patient satisfaction, reduces the risks of non- adherence, and improves patients' healthcare outcomes (Walters-Salas, 2012). Our study supported their study. We found out that patients were satisfied with the healthcare professional's care at the hospital; the patients have admitted during their treatment made them comfortable coming for another appointment.

On the other side of it, this study found that most patients detected their cancer unintentionally. This finding is in line with the claim by Orrason et al.,saying that despite increased use of screening mammography, a large percentage of breast cancers detected their cancer themselves. (Orrason et al., 2017). However, many patients tend to hide it from their family members for several reasons similar to Alzahrani et al. 2018. Some of them were diagnosed at a very late stage due to their hesitation to go to the doctors by perceiving that it was just a common symptom which would be healed as time passed. This attitude also supported by Lancet 2010, where they found many patients ignored the signs of cancer. Cultural, attitudes towards seeking medical care, fear and embarrassment of a cancer diagnosis, and difficulties navigating the healthcare system all play a part (Lancet 2010). This finding is very much aligned with our conclusion in this study. The patients' attitude in ignoring the symptom due to cultural perspective, such as better not knowing than knowing is not acceptable behavior in cancer care.

\subsubsection{Health belief on cancer, its treatment effectiveness for cancer healing.}

Most patients believed that cancer is due to genetic, environment, stress and sinful lifestyle. However, they were still patients saying that cancer is due to bacteria. Yet none of them perceived cancer is a taboo or punishment for bad conduct by God. None of them also said that cancer is due to some evil spirits. Most patients perceived that cancer could be healed by conventional treatment. According to the health belief model (HBM), patients' decision making on cancer and treatment were based on four perceived susceptibility, perceived severity, perceived benefits, and perceived barriers. The more they belief that the treatment can be cured the more they would belief on the treatment effectiveness and would comply to the treatment more (Herrmann, Hall, \& Proietto, 2018). This study revealed 
that patients' understanding of cancer and cancer treatment's effectiveness aligns with the HBM theory. The severity of the disease also plays an essential role in the treatment's decision making.

On top of that, if they believe that the treatment can benefit them more than harm, they would go for it. However, some barriers limit them from taking medicine. Most of the obstacles were related to socioeconomic rather than health belief.

\subsubsection{Barriers for conventional cancer treatment.}

This study's finding is in line with the survey conducted by Gonzalo et al., 2017, where payment policies, cannot drive, cannot speak the national language and limit them to go for treatment.

\subsubsection{Cues to action.}

This study revealed that cancer patients seek the various way of coping with their stress. Friends, family, and spirituality seem to be supportive. This finding is supported by $\mathrm{Ng}$ et al. 2017, who conducted a study on 400 Malaysian breast cancer patients in Malaysia. They stated that family members could be supportive, especially in decision making and emotional support for cancer patients. Many articles found to be supportive of our findings.(Layionava et al., 2018).

\subsection{Conclusion}

This qualitative exploration concluded that patients still lack in knowledge about cancer. However, they take cancer very positively. Patients showed a very positive attitude toward the treatment they received and believed it would cure their cancer. They complied and followed the doctor's instruction. Most of them used their way of Cancer coping, and they claimed for them. Seeking spiritual healer and socialization are some of the methods found in this study.

Some barriers limit them to assess the treatment comfortably, but they tried hard to comply with the treatment by seeking supports from family and friends. NGO like MAKNA helps but not all. In conclusion, our study found out that the patients still need a lot of support from the health care team in term of physical and psychological well-being. They need supports from the NGOs for the socioeconomic status. The health care team and the caregivers should coordinate in delivering enough knowledge for the patients to expect the positive and negative circumstances as a cancer patient. There are barriers that limit them to assess to the treatment comfort, but they tried hard to comply to the treatment by seeking supports from family and friends. NGO like MAKNA helps but not all. As a conclusion, our study found out that, the patients still need a lot of support from the health care team in term of physical and psychological well-being. They need supports from the NGOs for the socioeconomic status. The health care team and the care givers should coordinate in delivering enough knowledge for the patients so that they are expecting the positive and negative circumstances as a cancer patients. This finding can help the policy maker to design a proper education and awareness program at every level of community to make the campaign successful.

\section{Limitation}

This study is a qualitative exploration. It cannot represent or conclude the whole cancer patients in Malaysia. However, this finding can give a piece of insight information for further quantitative investigation in future.

\section{Acknowledgments.}

We would like to thank Universiti Teknologi MARA, Cawangan Pulau Pinang for supporting the paper's presentation. We also would like thank all the patients who participated in the study. Not to forget to all nurses and Puan Azlina Abdullah from MAKNA who introduce the patients for this study..

\section{References}

Alzahrani AS, Alqahtani A, Alhazmi M, Gaafar R, Bajabir D, Alharbi IM, Alharbi AMF, Kheshaifaty G, Alzahrani A (2018). Attitudes of cancer patients and their families toward disclosure of cancer diagnosis in Saudi Arabia: a Middle Eastern population example: Patient Preference and Adherence Volume 2018:12 Pages 1659-1666

Berger, O., Grønberg, B. H., Loge, J. H., Kaasa, S., \& Sand, K. (2018). Cancer patients' knowledge about their disease and treatment before, during and after treatment: A prospective, longitudinal study. BMC Cancer. https://doi.org/10.1186/s12885-018-4164-5

Chaka, B., Sayed, A. R., Goeieman, B., \& Rayne, S. (2018). A survey of knowledge and attitudes relating to cervical and breast cancer among women in Ethiopia Jeffrey v Lazarus. BMC Public Health. https://doi.org/10.1186/s12889-018-5958-8

Che Noriah Othman and Maryam Farooqui (2018). Traditional and Complementary Medicine: Perspective of patients in Sabah, Malaysia. Journal of Asian Behavioral Study. Vol. 3 No. 10 (2018): Sep / Oct.

Gonzalo, M. B., House, L., Santiago, K., Buzaglo, J. S., Zaleta, A. K., \& Gupta, N. K. (2017). Access to care in cancer: Barriers and challenges. Journal of Clinical Oncology. https://doi.org/10.1200/jco.2017.35.8_suppl.33 
Herrmann A, Hall A, Proietto A (2018). Using the Health Belief Model to explore why women decide for or against the removal of their ovaries to reduce their risk of developing cancer. BMC Womens Health. 14;18(1):184. doi: 10.1186/s12905-018-0673-2.

Khan, T. M., Leong, J. P. Y., Ming, L. C., \& Khan, A. H. (2015). Association of knowledge and cultural perceptions of Malaysian women with delay in diagnosis and treatment of breast cancer: A systematic review. Asian Pacific Journal of Cancer Prevention, 16(13), 5349-5357. https://doi.org/10.7314/APJCP.2015.16.13.5349

Kishore J. Ahmad I. Kaur R. and Mohanta P. K. (2008). Beliefs and perceptions about cancers among patients attending radiotherapy OPD in Delhi, India. Asian Pacific journal of cancer prevention: APJCP 9(1):155-8

Korkut Y. (2019). Assessment of knowledge, attitudes, and behaviors regarding breast and cervical cancer among women in western Turkey. J Int Med Res. ;47(4):16601666. doi: 10.1177/0300060519830252.

Lancet, T. (2010). Late-stage cancer detection in the USA is costing lives. The Lancet, 376(9756), 1873. https://doi.org/10.1016/S0140-6736(10)62195-2

Laryionava, K., Pfeil, T. A., Dietrich, M., Reiter-Theil, S., Hiddemann, W., \& Winkler, E. C. (2018). The second patient? Family members of cancer patients and their role in end-of-life decision making. BMC Palliative Care. https://doi.org/10.1186/s12904-018-0288-2

Laxmi, S., \& Khan, J. A. (2013). Does the cancer patient want to know? Results from a study in an Indian tertiary cancer center. South Asian Journal of Cancer.

Lim, G. C. C. (2002). Overview of cancer in Malaysia. Japanese Journal of Clinical Oncology, 32 Supp/(Supplement 1), 37-42. https://doi.org/10.1093/jjco/hye132

Marmarà, D., Marmarà, V., \& Hubbard, G. (2017). Health beliefs, illness perceptions and determinants of breast screening uptake in Malta: A cross-sectional survey. BMC Public Health. https://doi.org/10.1186/s12889-017-4324-6

Maryam, F., Mohamed A, H., Aishah, K. S., Asrul, A. S., Tan, B. S., \& Muhammad A, F. (2011). A qualitative exploration of Malaysian cancer patients' perspectives on cancer and its treatment. BMC Public Health. https://doi.org/10.1186/1471-2458-11-525

Ng, G. C., Mohamed, S., Sulaiman, A. H., \& Zainal, N. Z. (2017). Anxiety and Depression in Cancer Patients: The Association with Religiosity and Religious Coping. Journal of Religion and Health, 56(2), 575-590. https://doi.org/10.1007/s10943-016-0267-y

Nikbakhsh, N., Moudi, S., Abbasin, S., \& Khafri, S. (2014). Prevalence of depression and anxiety among cancer patients. Caspian Journal International Medical.

Norsa'adah, B., Rampal, K. G., Rahmah, M. A., Naing, N. N., \& Biswal, B. M. (2011). Diagnosis delay of breast cancer and its associated factors in Malaysian women. BMC Cancer. https://doi.org/10.1186/1471-2407-11-141

Orrason, A. W., Sigurdsson, M. I., Baldvinsson, K., Thorsteinsson, H., Jonsson, S., \& Gudbjartsson, T. (2017). Incidental detection by computed tomography is an independent prognostic factor for survival in patients operated for nonsmall cell lung carcinoma. ERJ Open Research. https://doi.org/10.1183/23120541.00106-2016

Paskett ED, Tatum C, Rushing J, Michielutte R, Bell R, Foley KL, Bittoni M, Dickinson S (2004). Racial differences in knowledge, attitudes, and cancer screening practices among a triracial rural population. Cancer. $2004 \operatorname{Dec} 1 ; 101(11): 2650-9$.

Tapera, O., Dreyer, G., Kadzatsa, W., Nyakabau, A. M., Stray-Pedersen, B., \& Sjh, H. (2019). Cervical cancer knowledge, attitudes, beliefs and practices of women aged at least 25 years in Harare, Zimbabwe. BMC Women's Health. https://doi.org/10.1186/s12905-019-0790-6

Walters-Salas, T. (2012). The challenge of patient adherence. Bariatric Nursing and Surgical Patient Care. https://doi.org/10.1089/bar.2012.9960 